\title{
The Validity of CAPM: A Critical and Conclusive Study with Empirical Evidence from the UK Security Market
}

\author{
Siman Peng ${ }^{1, *}$ \\ ${ }^{1}$ Business School, University of Edinburgh, EH8 9JS, Edinburgh, Scotland, United Kingdom \\ *Corresponding author. Email: s1821603@ed.ac.uk
}

\begin{abstract}
CAPM is a fundamental asset pricing model that has complex viewpoints from scholars. The validity of CAPM is essential for the market participants, as many of their decisions will be based on the securities' estimated returns. This paper aims to give a more comprehensive discussion of CAPM and test its application in real life. By reviewing the developments and showing the empirical evidence, the two-pass regression results from both the stocks and funds from the UK's capital market prove that inconsistencies occur. Significant alphas may pose arbitrage opportunities for the market participants to exploit, while the other differences are statistically insignificant. The discoveries imply that generally, CAPM can be a useful tool to price assets and aid decision-making in some cases. However, users should be aware of its unrealistic assumptions and inaccurate predictions. The regression result may be specific due to the choice of country, sample size, industry, security type, and time interval. Previous research has evidenced that CAPM has multiple limitations when applied in the real market, meaning weak validity in pricing assets.
\end{abstract}

Keywords: CAPM, asset pricing model, two-pass regression, empirical evidence.

\section{INTRODUCTION}

The pricing of assets is an essential part of finance, and it heavily links with portfolio components and investment strategies. The Markowitz portfolio theory has laid the foundations for financial investments, and it points out the relationship between risk and return. Building on the Markowitz diversification theory and the modern portfolio theory, the CAPM model was proposed by William. F. Sharpe [1], Jack Treynor [2] and some other scholars. When the security market functions efficiently, the investors will be compensated for taking risks. Remarkably, CAPM has lots of additional assumptions, which are not realistic indeed. These drawbacks may hinder its validity and make it hard to be applied in reality.

CAPM assumes that the solely priced risk factor is the market risk, denoted as $\beta$, and the price for the beta will be the market premium, which is the difference between the market interest rate and the risk-free rate. Meanwhile, the model illustrates the trade-off between security's systematic risk and return. Extra returns will not reward the diversifiable standard deviations. The investors can diversify by adding securities of non-zero correlations with the existing stocks.

CAPM has been widely used in the industry in predicting security returns. Specifically, firms may substitute the project beta into the formula and get a prediction of the cost of capital. At the same time, investors can estimate their return of capital in the same way.

However, the model has consistently been developed and tested, and researchers found different results on whether CAPM is valid or not. The unrealistic assumptions and inherent mistakes all bring conflicts and arguments [3]. The studies also pointed out that using CAPM can lead to wrong predictions in many cases. This study will do a two-pass regression with data from the UK's security market to test CAPM's validity in real life. The result proves that the stock data from the real market does not match CAPM's assumptions.

The paper will first introduce the development of CAPM and then present the two-pass regression analysis for the UK's securities, before discussing the application of CAPM in financial markets, and finally provide a critical conclusion. 


\section{THE DEVELOPMENT OF CAPM}

\subsection{Markowitz Portfolio Theory}

Markowitz's portfolio theory lays the cornerstone for investments. Many following theories and models have built on that. In light of the Markowitz Portfolio optimization model, there are countless risky assets in the market. Rationale investors will only invest in the assets that are on the efficient frontier to maximize their returns. For any level of return, the point on the minimum variance frontier has the lowest level of risk, and it defines the absolute best return that can be achieved for any level of return [4].

Regarding the portfolio, every investor should invest in a risk-free asset and the universal same risky portfolio, and the construction should be implemented in the following process. First, analyze the risk and returns of the universe of available assets and identify the available combinations. This could be done through top-down or bottom-up analysis. The expected return (E(r)) for every asset and their covariance matrix should be computed to get the minimum variance frontier. To obtain the lowest possible variance from a specific level of expected return, investors should do diversifications, as individual assets are not that efficient. The second step would be to find out the optimal risky portfolio, which lets the capital allocation line tangent to the efficient frontier. The investor would then consider the weight between the risky portfolio and the optimal risky asset, decided based on personal risk aversion. The investment strategy in Markowitz essentially means the Separation property. The optimal risky portfolio, which has the highest Sharpe ratio, is the same for everyone, and the degree of risk awareness only plays a part when deciding the investment weight.

\subsection{Single index model}

Unlike the Markowitz model, which has multiple inputs of expected return, standard deviation, and correlation coefficient, the single-index model (SIM) has simplified the mean-variance and return estimation process. Only the $\alpha, \beta$, $e$ needs to be estimated for each individual asset. Therefore there will be a huge difference in inputs number between Markowitz and SIM, as the number of assets increases [5].

Table 1. Inputs of SIM and Markowitz

\begin{tabular}{|c|c|c|c|c|c|c|c|}
\hline Assets & $\alpha \mathrm{i}$ & $\beta \mathrm{i}$ & $\sigma^{\wedge} 2$ ei & $\overline{\mathrm{r}} \mathrm{m}$ & $\sigma^{\wedge} 2 \mathrm{~m}$ & SIM & Markowitz \\
\hline 2 & 2 & 2 & 2 & 1 & 1 & 8 & 5 \\
\hline 3 & 3 & 3 & 3 & 1 & 1 & 11 & 9 \\
\hline 4 & 4 & 4 & 4 & 1 & 1 & 14 & 14 \\
\hline 5 & 5 & 5 & 5 & 1 & 1 & 17 & 20 \\
\hline 10 & 10 & 10 & 10 & 1 & 1 & 32 & 65 \\
\hline 50 & 50 & 50 & 50 & 1 & 1 & 152 & 1325 \\
\hline 100 & 100 & 100 & 100 & 1 & 1 & 302 & 5150 \\
\hline 500 & 500 & 500 & 500 & 1 & 1 & 1502 & 125750 \\
\hline $\mathrm{N}$ & $\mathrm{N}$ & $\mathrm{N}$ & $\mathrm{N}$ & 1 & 1 & $3 N+2$ & 1 \\
\hline
\end{tabular}

SIM implies that the correlations of securities commonly respond to the market movements. This correlation could be obtained by identifying the return on individual stock to the market portfolio's return.

Formula of SIM:

$$
R_{i}=\alpha_{i}+b_{i} R_{m}+e_{i}
$$

According to the SIM's formula, which is in the excess return form, $\alpha i$ is the stock's excess return that is irrelevant to the market performance, and it is an expected component. $R m$ is the market premium, while $\beta i$ measures how sensitive the stock's return is related to the Rm. Ei is the firm-specific risk. It's a random variable and is unexpected. Both $\alpha \mathrm{i}$ and $\mathrm{Ei}$ are independent of the market. The model has two key assumptions: 1. The degree of error term does not relate to the value of the market return. 2 . The expected return of individual stocks is uncorrelated; the only correlate source is the market return variable they have in common.

\subsection{CAPM}

The establishment of CAPM symbolizes the beginning of asset pricing theory. CAPM builds on both Markowitz and SIM. Though the mathematical formula between SIM and CAPM differs very little, CAPM has 
some additional assumptions. The unique 'equilibrium' setting illustrates the asset pricing, and the pricing will be corrected if it is not in equilibrium. The model presents how investors should make their investment decisions and how the returns should be determined. According to CAPM's principle, all investors will hold identical views about the securities, and they maximize their portfolios based on Markowitz's portfolio selection model.

According to the above model, a comparison analysis for these different models will be presented. The difference between the single-index model and CAPM is that CAPM has an equilibrium solution when depriving the structure of how returns are formed. It has an encompassing and strong statement for the market equilibrium, while SIM does not. In CAPM's equilibrium for the entire ecosystem and entire investable universe, together with all investors, the asset returns should only depend on the systematic risk.

Unlike the other two models, no structure (essentially no equation) is imposed on Markowitz, nor does the formations of expected returns or what they depend on. The expected return of stocks is estimated from the historical data, and any factor may bring influence.

By understanding the features of CAPM, investors could better adjust the composition of their portfolios. For instance, if the investor demands a high return, he needs to choose the stock with the high beta or offset the risk by reducing the high-beta stocks. The financial analysts could use CAPM to detect the equilibrium returns and security price, or they may exploit the arbitrage opportunity if alphas exist. Additionally, company managers could use CAPM to calculate the capital cost and aid their investment strategies. They may invest in projects which have a return that's higher than the cost of capital. However, Jagannathan and Meier [6] claimed that using the input of historical market excess return may exaggerate the cost of capital.

CAPM's unique assumptions bring conclusions that are different from other models. Some particular assumptions will be discussed here.

The very basic assumption is that the investors are rational. They maximize their utility by optimizing the mean variance. That is, the utility level will only depend on the risk and return. However, this can be easily violated in reality. Investors are often irrational and subject to behavioral bias. In CAPM, investors would assess the mean, variance, and covariance and formulate the minimum variance frontier. Because of the assumption that investors can borrow and lend at a riskfree rate, investors can then find the portfolio that provides the highest risk-return. It is because the optimal portfolio has changed to the market portfolio, the original Capital allocating line will become the
Capital market line since it has the highest Sharpe ratio. All of the idiosyncratic risks are eliminated through diversification. Thus the assets are all efficient. In this case, investors should not consider the non-systematic risk anymore, the only aspect of securities that need to be concerned is the expected return and systematic risk (measured by beta), which is graphically presented by the security market line (SML). The equilibrium setting therefore occurs [7].

Another assumption of CAPM is that all assets are available to the public for exchange. Since all investors will invest in the identical risky portfolio, and it is because there is no mispricing in CAPM, the optimal risky portfolio becomes the market portfolio that contains all assets in the investable universe. The investors will only hold the market portfolio and the risk-free asset.

Besides, the proportion of the risky portfolio will have the same number as the weight that the investors invested in. In reality, there will be hidden information and unpublicized assets, investors will not be able to invest in all assets, so the market portfolio never exists.

Investors need to pay the transaction cost to exploit the benefit when there is the mispricing of assets. CAPM assumes there's no transaction cost in the market. Therefore, through the price adjustment, all stocks included in the optimal portfolio will be at the exact price they should be. However, the transaction cost will not be zero in real life, and the transaction cost may sometimes be higher than the benefit that the investor can reap from the mispricing. Therefore the investors stopped exploiting, and the mispricing stays. In that case, the securities are mispriced, and CAPM does not hold.

CAPM's assumptions of the individual investors and Market structures are not realistic. The model is in a vacuum and will be clashed once a single assumption is obeyed.

\section{REGRESSION ANALYSIS}

The two-pass regression is used to explore whether the results from the regression are consistent with the prediction from CAPM, for instance, whether beta truly explains the asset return significantly or whether the beta coefficient is exactly the historical market risk premium as suggested by CAPM [8].

\subsection{Method}

The two-pass regression is separated into two parts, the first-pass regression and the second-pass regression. The sample data should first be collected from the historical returns. To create a CAPM setting, the monthly closing price for each asset is collected to calculate the returns for individual assets. The excess 
return for each stock is the difference between the asset's total return and the risk-free rate. Besides, a market index will proxy the market portfolio, and government security will proxy the risk-free asset.

The first pass regression, a time series multiple regression, will be run to estimate the $\beta$ for every asset. The regression can be viewed as the Security Market Line (SML) equation, and the asset excess return is regressed on the market premium to estimate the responsiveness of the asset return on the market index.

$$
R_{i t}-R_{f t}=\alpha_{1}+b_{i}\left(R_{m t}-R_{f t}\right)+e_{i t}
$$

The results from the previous regression will be saved for the second pass regression. In this crosssectional test for CAPM, the Rit-Rft will then be regressed on $\beta \mathrm{i}$ to test whether they have a linear relationship. This is to explore how much does the asset return change when the beta changes.

$$
\overline{R_{l}-R_{f}}=\gamma_{0}+\gamma_{1} b_{i}+\gamma_{2} b_{i}^{2}+\gamma_{3} \sigma_{e i}^{2}+\epsilon_{i t}
$$

The regression results will be compared with CAPM's assumptions. If CAPM holds, $\gamma_{0}$ will be zero since all assets should be in equilibrium, $\gamma_{1}$ will equal to $\overline{R_{m}-R_{f}}$, and both $\gamma_{2}$ and $\gamma_{3}$ will equal to 0 , as there should not be any non-linear variables and nonsystematic risks.
This regression tests two types of assets, stock and ETF fund, and 100 individual data for each category will be collected. The returns, excess returns, and market premium will be computed in Python, while the regressions will be done in Stata.

\subsection{Data}

As the regression is based on the UK's stock market, the risk-free asset is represented by the UK gilt, and $\mathrm{S} \& \mathrm{P} 500$ is used as a proxy for the market index. The sample data for the stocks are the top 100 public holding stocks of the SPDR Series Trust, and the data for the funds will be 60 randomly selected ETFs. All data are downloaded from Capital IQ.

The prices for both assets returns will have a time interval from December 2016 to December 2019. Since the returns are calculated from the price, there will be 36 returns in total (January 2017 to December 2019).

\subsection{Result}

According to the regression outcome, the market premium is 0.00926 .

(1) Regression output for the stocks

\begin{tabular}{|c|c|c|c|c|c|c|}
\hline Source & SS & df & MS & Number of obs & 100 & \\
\hline & & & & $\mathrm{F}(3,96)$ & 0.42 & \\
\hline Model & 0.000042278 & 3 & 0.000014093 & Prob $>F$ & 0.7412 & \\
\hline \multirow[t]{2}{*}{ Residual } & 0.003254359 & 96 & 0.0000339 & R-squared & 0.0128 & \\
\hline & & & & Adj R-squared & -0.018 & \\
\hline Total & 0.003296637 & 99 & 0.000033299 & Root MSE & 0.00582 & \\
\hline ave & Coef. & Std.Err & $\mathbf{t}$ & $\mathbf{P}>|\mathbf{t}|$ & 【95\% Confidence & terval】 \\
\hline beta & 0.0016649 & 0.008003 & 0.21 & 0.836 & -0.0142209 & 0.0175507 \\
\hline beta_sq & 0.0000298 & 0.0060105 & 0.00 & 0.996 & -0.011901 & 0.0119606 \\
\hline rmse & 0.0550483 & 0.076967 & 0.72 & 0.476 & -0.0977301 & 0.2078267 \\
\hline _cons & 0.0093585 & 0.0038083 & 2.46 & 0.016 & -0.0017992 & 0.0169179 \\
\hline
\end{tabular}

Table 2. Regression result for the stocks

The constant variable is essentially the alpha. Though the figure is very small, it is statistically significantly different from 0 , as indicated by the $\mathrm{p}$ value, which is less than 5\%. This can also be seen from the $95 \%$ confidence interval as the results are not noisy, alphas are constantly larger than 0 . Therefore, $\gamma_{0}$ does not comply with CAPM's assumption. A $0.9 \%$ monthly alpha implies the asset does not lie on the SML, and a $10.8 \%$ annual alpha is extensive. The alpha makes the stocks under-priced, and hence, outperforms the market, and the financial managers can exploit the advantage.

For $\gamma_{1}$, The t-statistic is -0.949 , which is less than the critical value (2) at $95 \%$. Hence, the beta coefficient from the regression is not statistically significantly different from the average market risk premium 0.00926 , and the null hypothesis of $\gamma_{1}=$ market premium is not rejected. Though the assumption still holds, the estimated SML will be flatter than CAPM's 
prediction since the slope is smaller than the mean excess return of the market portfolio. Besides, the change of the stock return is less volatile compared to the market changes

For the coefficient of the beta square, the t-statistic for $\gamma_{2}$ is $0.0000298 / 0.0060105=0.0049$, lower than the critical value at $95 \%$ confidence level, which is 2 . Thus, the null hypothesis that $\gamma_{2}=0$ is not rejected, $\gamma_{2}$ is not statistically significantly different from 0 , though the figure 0.0000298 indicates that there's a slight curvature relationship between the market and the nondiversifiable risk.

For the coefficient of the non-systematic risk, the tstatistic for $\gamma_{3}$ is 0.72 , and it's smaller than the critical value, 2 . As a result, the null hypothesis that gamma $3=$ 0 is accepted. The coefficient of firm-specific risk from the regression is not statistically significantly different from 0, which is consistent with the CAPM that nonsystematic risk should not be priced.

(2) Regression output for the funds

Table 3. Regression result for the fund

\begin{tabular}{|c|c|c|c|c|c|c|}
\hline Source & SS & df & MS & \multirow{2}{*}{$\begin{array}{l}\text { Number of obs } \\
\mathrm{F}(3,96)\end{array}$} & \multicolumn{2}{|l|}{60} \\
\hline & & & & & & \\
\hline Model & 0.00029636 & 3 & 0.000098787 & Prob $>F$ & 0.0155 & \\
\hline \multirow[t]{2}{*}{ Residual } & 0.001466222 & 56 & 0.000026183 & R-squared & 0.1681 & \\
\hline & & & & Adj R-squared & 0.1236 & \\
\hline Total & 0.001762583 & 59 & 0.000029874 & Root MSE & 0.00512 & \\
\hline ave & Coef. & Std.Err & $\mathbf{t}$ & $\mathbf{P}>|\mathbf{t}|$ & 【95\% Confidence In & val] \\
\hline beta & 0.0046667 & 0.0080335 & 0.58 & 0.564 & -0.0114264 & 0.207597 \\
\hline beta_sq & 0.0017593 & 0.0042655 & 0.41 & 0.682 & -0.0067855 & 0.0103042 \\
\hline rmse & -0.0015334 & 0.0661445 & -0.02 & 0.982 & -0.1340368 & 0.13097 \\
\hline _cons & 0.0035516 & 0.0041258 & 0.86 & 0.393 & -0.0047134 & 0.0118166 \\
\hline
\end{tabular}

For alpha, the t-statistic is 0.86 , smaller than the critical value at $95 \%$, which is 2 . Therefore, the alpha of the funds is not statistically significantly different from 0 . Besides, the $95 \%$ confidence interval indicates the estimate is very noisy, and is not possible to figure out if the results are larger or lower than 0 in most of the time. Consequently, the null hypothesis of $\gamma_{0}=0$ for the funds is accepted. A $0.35 \%$ monthly alpha means $0.35 \% * 12=4.2 \%$ alpha per year. Although it is extensive and makes the funds outperform the market, it is not statistically significantly different from 0 .

The t-statistic is -0.57 , and this is smaller than the critical value at $95 \%$. Therefore, the coefficient of the funds is not statistically significantly different from the average market risk premium, and the null hypothesis is that $\gamma_{1}=$ market premium is not rejected. In this case, the estimated SML will be flatter than predicted by the CAPM since gemma 1 is smaller than the average risk premium. The change of the fund is less volatile when the market changes.

The t-statistic for gamma 2 is 0.041 , lower than the critical value at the $95 \%$ confidence level of 2 . Consequently, the null hypothesis that gemma $2=0$ is not rejected. There may be a very tiny curvature since the coefficient of the beta square is 0.0017593 , but this is not statistically significantly different from 0 .

The t-statistic for gamma 3 is -0.02 , smaller than the critical value of 2 . Therefore, the null hypothesis that gamma $3=0$ is not rejected, the coefficient of firmspecific risk is not statistically significantly different from 0 . There's no statistically significant relationship between the excess return and non-systematic risk, consistent with the CAPM that non-systematic risk should not be priced.

\subsection{Discussion}

There are slight inconsistencies, as seen from the regression results. A lot of factors could bring an impact. The beta of funds is higher than the beta of stocks, meaning that funds move closer with the market, which may be impacted by the chosen industry. For instance, many of the funds are related to health care, and if the market is performing well, people will pay more attention to healthcare, so the beta would be higher.

Besides, the external factor may cause the inconsistencies, since CAPM itself has some inherent limitations that impact the test result. According to 
Roll's critique [9], there is the benchmark that the market portfolio never exists in real life. There is no such portfolio that contains all the available investment assets. Therefore, when the S\&P 500 is used in the regression, it is biased, and an efficient proxy does not mean a real efficient market portfolio. That also implies CAPM is not testable unless the exact composition of the market portfolio is known.

Moreover, the betas in the first pass regression are estimated using the S\&P 500, while it is not the true market index, but betas are then used in the second pass regression, bringing a tautology. Moreover, if beta, the right-hand side variable, is measured inaccurately, the slope will be biased larger, and the intercept will be smaller. In other words, if betas are calculated against such portfolios, they will satisfy the SML relation exactly whether or not the real market portfolio is meanvariance efficient in the ex-ante sense [10].

Besides, there can also be estimation error in the raw data and the first pass regression, which makes the conclusion subject to doubt and confidence interval. The other assumptions of CAPM also cannot be satisfied in this regression, such as the borrowing rate cannot be risk-free, therefore using the real-life data, in this case, would be validated.

The characteristics of the dataset would also bring a difference to the result of the two datasets. The smaller sample size of my stock may decrease the precision of the test of average returns. Moreover, as the stocks are the top 100 holding companies, the CAPM's test result may not represent the whole holding companies, therefore not depicting a comprehensive picture. Besides, as the stocks all belong to the holding companies of an ETF, there may be high covariance between the stocks that would impact the regression result.

Furthermore, the inconsistency with CAPM may be caused because the existing factor, beta, does not reward some of the risks taken. For instance, there could be a factor from the firm size and the value of the stock. As indicated by Nwani's study [11], beta hardly explains the variation of the security returns. Therefore beta plays an insignificant role as a pricing factor, and stocks in the UK may be more sensitive to other factors. In this case, an extended version of the asset pricing model may be preferred, such as the three-factor model or the five-factor model.

The result of this regression test is consistent with the previous study in India. By using the 5-year returns of 10 top companies from the Indian Stock Market, Ratra [12] found out that there is a considerable difference between the actual return and the expectation at the normal risk level. Therefore, the application of CAPM may misguide the investors to have an inaccurate expectation of the stock movements and therefore bring wrong investment decisions. This also proves CAPM's weak applicability in the real stock market. Similarly, according to Agarwal's study [13], CAPM does not hold in a specific sector (the automobile sector) in India. The data reveals that higher beta does not necessarily lead to higher return, and there's also a difference between market excess return and the estimated values. Though in a one-year period of his study, CAPM is not clearly rejected, beta is linearly related to the return, which is consistent with CAPM's predictions. Therefore, the author reckons that though the beta is a useful factor, it is insufficient to predict the asset return. There could be any other macroeconomic factors or firm-specific factors impacting the securities.

\section{CONCLUSION}

CAPM is the basic asset pricing model that has been widely used in the financial investment field. A majority of market participants use that to decide the composition of their portfolios and further investment decisions. The model is particularly used to price risky assets and estimate the expected returns.

This study gave a general review of the development of CAPM. It tested the model's validity by doing a twopass regression using the data of the funds and stocks from the UK's security market. The results illustrate that most of the assumptions of CAPM hold, except that the alpha for the stock is statistically significantly different from 0 . This could lead to arbitrage opportunities, and investors may beat the market by exploiting the alpha. Other variables all comply with the prediction of CAPM, implying that CAPM still holds under most of the situations. The finding is insightful for different kinds of market participants, such as the investors, financial analysts, and firm managers, since they all make relevant decisions or suggestions based on the prediction from CAPM. However, users should be aware that the test result is subject to many constraints, for example, the security type, time intervals, the relevant country, the sample size, and the proxies used. The market participants will then have a better understanding of the applicability of CAPM, including its advantages and drawbacks. When applying CAPM in real life, users could consider the expanded asset pricing models or other tools to get a more accurate result, or they should bear the possible inconsistencies in mind. The discovery is important as it provides the empirical evidence of CAPM and presents the coefficients of variables from real data.

In the future, research may pay more attention to the prediction of Stocks in the more advanced settings. For instance, high-frequency trading and fintech have developed rapidly in recent eras. CAPM as the fundamental asset pricing model could be studied deeply to chase the new trend of securities. Studying 
how suitable the model is in the highly technical stock market nowadays will be insightful.

\section{REFERENCES}

[1] Sharpe, W. (1964). Capital Asset Prices: A Theory of Market Equilibrium under Conditions of Risk. The Journal Of Finance, 19(3), 425. doi: $10.2307 / 2977928$.

[2] Treynor, J. (1961). Market Value, Time, and Risk. SSRN Electronic Journal. doi: 10.2139/ssrn.2600356.

[3] Fernandez, P. (2014). CAPM: An Absurd Model. SSRN Electronic Journal. doi: 10.2139/ssrn.2505597.

[4] Solanki, D. (2011). Portfolio Selection Process through Markowitz Model. Indian Journal Of Applied Research, 4(8), 356-358. doi: $10.15373 / 2249555 x$ /august2014/90.

[5] Fernandez, Desai, R., \& Surti, M. (2012). Optimum Portfolio Construction: Sharpe Single Index Model. International Journal Of Scientific Research, 2(9), 250-251. doi: $10.15373 / 22778179 /$ sep2013/82.

[6] Jagannathan, R., \& Meier, I. (2002). Do We NeedCAPM for Capital Budgeting?. Financial Management, 31(4), 55. https://doi.org/10.2307/3666174.

[7] Fama, E., \& French, K. (2003). The Capital Asset Pricing Model: Theory and Evidence. SSRN
Electronic Journal. doi: 10.2139/ssrn.440920[11] Nwani, C. (2021). CAPM Beta and the UK Stock Returns. International Journal Of Science And Research (IJSR).

[8] Ahn, S., Gadarowski, C., \& Perez, M. (2009). TwoPass Cross-Sectional Regression of Factor Pricing Models: A Minimum Distance Approach. SSRN Electronic Journal. doi: 10.2139/ssrn.1518086.

[9] Roll, R., 1977. A critique of the asset pricing theory's tests Part I: On past and potential testability of the theory. Journal of Financial Economics, 4(2), pp.129-176.

[10] French, J. (2017). The One:A Simulation of CAPM Market Returns. The Journal Of Wealth.

[11] Nwani, C. (2021). CAPM Beta and the UK Stock Returns. International Journal Of Science And Research (IJSR).

[12] Ratra, D. (2017). Application of Capital Asset Pricing Model in Indian Stock Market. Vandana Management, 20(1), 126-147. doi: 10.3905/jwm.2017.20.1.126 Publication, 7(2), 1-7. Retrieved 25 August 2021.

[13] Agarwal, R. (2021). TESTING PRACTICAL APPLICATION OF CAPM: A STUDY OF STOCKS OF AUTOMOBILE SECTOR USING CNX AUTO INDEX IN NSE. International Journal Of Advanced Research In Management And Social Sciences, (2278-6236). Retrieved 25 August 2021. 